\title{
Gross Morphometrical Studies on the Brain of Kadaknath Fowl in Growing Period
}

\author{
S. K. Joshi ${ }^{1 *}$, J. Udgata ${ }^{1}$, S. Sathapathy ${ }^{2}$ and S. K. Sahu ${ }^{2}$ \\ ${ }^{1}$ Krishi Vigyan Kendra, OUAT, Jharsuguda - 768202, India \\ ${ }^{2}$ Department of Anatomy and Histology, CVSc. \& A.H., OUAT, Bhubaneswar - 751003, India \\ *Corresponding author
}

Keywords

Brain, gross, grower, Kadaknath, morphometry

Article Info

Accepted:

12 August 2019

Available Online:

10 September 2019

\section{A B S T R A C T}

The present gross morphometrical study was carried out on the brain of six healthy birds of Kadaknath Fowl in growing period ( 7 weeks to 16 weeks). The birds were procured from the Central Poultry Development Organization (CPDO), Eastern Region, Bhubaneswar and the research work was conducted at Krishi Vigyan Kendra, Jharsuguda, OUAT. It was found that the brain of Kadaknath fowl subdivided into cerebrum, cerebellum and medulla oblongata. It was found that the average maximum length and width of the brain were found to be $(3.2 \pm 0.124)$ $\mathrm{cm}$ and $(2.9 \pm 0.091) \mathrm{cm}$ respectively. The right olfactory bulb was longer and wider than the left one. Similarly, the right optic lobe was larger than the left one. The average length of longitudinal intercerebral groove was measured as $(1.9 \pm 0.025) \mathrm{cm}$. The average width of longitudinal intercerebral groove was uniform at cranial, middle and caudal parts and found to be $(0.2 \pm 0.001) \mathrm{cm}$. Further, the average perimeter of middle vermis lobe of cerebellum was measured as $(2.6 \pm 0.194) \mathrm{cm}$. The present baseline data on various important parameters of brain of Kadaknath fowl in grower period would pave the way for further research in this field.

\section{Introduction}

Poultry production in India has taken a quantum leap in the last four decades, emerging from an unscientific farming practice to commercial production system with state-of-the art technological inventions (Tamilselvan et al., 2018). There is a tremendous development in the poultry industry in last few decades, but little attention has been paid for indigenous chicken, due to its poor producing ability (Kumar et al., 2018). Total poultry population of India was estimated to be 700 million, out of which about 10 to $15 \%$ were indigenous or native breeds. There are about 20 indigenous breeds/varieties of chicken found in India. Backyard poultry farming is a part and parcel of typical rural/tribal household, touching social, cultural and economic aspects in India. Need of conservation and improvement of animal genetic resources has been globally 
accepted. Out of many indigenous poultry breeds, one well known breed named as Kadaknath or Kalamasi meaning the fowl having black flesh. Kadaknath is an important indigenous breed of poultry inhabitating vast areas of Western Madhya Pradesh mainly the Jhabua (Bendapudi, 2016) and Dhar Districts and adjoining areas of Gujarat and Rajasthan. There are three main varieties of Kadaknath breed. They are Jet black, pencilled and Golden Kadaknath (Parmar, 2003). The Jet black adult males and females are black in colour, the Golden adult male and females are basically black in colour with Golden feathers on head and neck, whereas in Pencilled variety adult male and female plumage is black with white feathers on neck. It is locally known as "Kalamasi" as it is having black flesh (Mahanta et al., 2018). The peculiarity of this breed is that most of the internal organs show the characteristic black pigmentation which is more pronounced in trachea, thoracic and abdominal air sacs, gonads, elastic arteries, at the base of the heart and mesentery. Varying degree of blackish colouration is also found in the skeletal muscles, tendons, nerves, meninges, brain and bone marrow (Das et al., 2018). Avian brain study is an emerging field in present era of biological studies. The present gross morphometrical study was carried out on the brain of Kadaknath fowl in growing period ( 7 weeks to 16 weeks) to establish a baseline data for this breed for future research.

\section{Materials and Methods}

The Kadaknath chicks were procured from the Central Poultry Development Organization (CPDO), Bhubaneswar. The chicks were reared at KVK, Jharsuguda, OUAT and six healthy birds were selected from grower stage (7 weeks to 16 weeks) to study the gross morphometrical features of brain. The head of the birds under study were carefully separated at the level of second cervical vertebrae
(Panigrahy et al., 2017). The cranial cavity was cut open very carefully with the help of scissors, forceps and scalpel. Then nasal bones and temporal bones were severed rostrally and laterally by the help of bone cutter. These separations were done up to the level of base of skull. All cranial nerve attachments were cut gently to separate the intact brain from insitu after detaching it from the spinal cord at the level of foramen magnum. The intact brain was removed from the cranial cavity after detaching it from the spinal cord at the level of foramen magnum. Then the meninges of brain were separated. After the collection, the intact whole brain samples were cleaned (washed) in normal saline solution and detail morphometrical studies were undertaken. The weight of whole brain and its different components were taken in digital weighing balance. Further, the volumes were measured by water displacement method. The measurements of different parameters of brain were taken with the help of scale, thread and digital weighing balance. The different biometrical parameters of brain measured were subjected to routine statistical analysis as per standard technique given by Snedecor and Cochran (1994).

\section{Results and Discussion}

The average maximum length of the brain (measured from cranial end of cerebral hemisphere to caudal end of medulla oblongata) was found to be $(3.2 \pm 0.124) \mathrm{cm}$. The average maximum width of the brain (highest distance between the lateral boarders of cerebral hemispheres) was found to be $(2.9 \pm 0.091) \mathrm{cm}$. The average cranio-caudal lengths of left and right cerebral hemispheres were found to be $(2.1 \pm 0.223) \mathrm{cm}$ and $(2.0 \pm 0.112) \mathrm{cm}$ respectively. The average widths of left cerebral hemisphere at cranial, middle and caudal parts were measured as $(0.6 \pm 0.021) \quad \mathrm{cm}, \quad(1.6 \pm 0.008) \mathrm{cm}$ and $(0.9 \pm 0.132) \mathrm{cm}$ respectively. Similarly, 
average widths of right cerebral hemisphere at cranial, middle and caudal parts were measured as $(0.5 \pm 0.015) \mathrm{cm},(1.2 \pm 0.023) \mathrm{cm}$ and $(1.1 \pm 0.019) \mathrm{cm}$ respectively. Further, the average thickness of left cerebral hemisphere at cranial, middle and caudal parts was found to be $(0.3 \pm 0.005) \mathrm{cm},(1.0 \pm 0.008) \mathrm{cm}$ and $(0.7 \pm 0.006) \mathrm{cm}$ respectively. Similarly, the average thickness of right cerebral hemisphere at cranial, middle and caudal parts was found to be $(0.6 \pm 0.002) \mathrm{cm},(1.1 \pm 0.008) \mathrm{cm}$ and $(0.9 \pm 0.010) \mathrm{cm}$ respectively. So, right cerebral hemisphere was comparatively thicker than the left one. The average perimeters of left and right cerebral hemispheres were found to be $(4.5 \pm 0.312) \mathrm{cm}$ and $(4.8 \pm 0.229) \mathrm{cm}$ respectively. The average length of longitudinal intercerebral groove was measured as $(1.9 \pm 0.025) \mathrm{cm}$. The average width of longitudinal intercerebral groove was uniform at cranial, middle and caudal parts and found to be $(0.2 \pm 0.001) \mathrm{cm}$.

The average cranio-caudal lengths of left and right olfactory bulbs were found to be $(0.4 \pm 0.001) \quad \mathrm{cm}$ and $(0.6 \pm 0.002) \mathrm{cm}$ respectively. The average widths of left olfactory bulb at cranial, middle and caudal parts were measured as $(0.1 \pm 0.001) \mathrm{cm}$, $(0.2 \pm 0.001) \mathrm{cm}$ and $(0.1 \pm 0.001) \mathrm{cm}$ respectively. Similarly, the average widths of right olfactory bulb at cranial, middle and caudal parts were measured as $(0.3 \pm 0.002)$ $\mathrm{cm},(0.5 \pm 0.001) \mathrm{cm}$ and $(0.3 \pm 0.001) \mathrm{cm}$ respectively. This suggested that the right olfactory bulb was longer and wider than the left one.

The average cranio-caudal diameters of left and right optic lobes were found to be $(1.0 \pm 0.010) \mathrm{cm}$ and $(1.1 \pm 0.008) \mathrm{cm}$ respectively. The average transverse diameters of left optic lobe at cranial, middle and caudal parts were measured as $(0.4 \pm 0.001) \mathrm{cm}$, $(0.9 \pm 0.003) \mathrm{cm}$ and $(0.5 \pm 0.002) \mathrm{cm}$ respectively. Similarly, average transverse diameters of right optic lobe at cranial, middle and caudal parts were measured as $(0.5 \pm 0.001) \quad \mathrm{cm}, \quad(1.0 \pm 0.012) \quad \mathrm{cm}$ and $(0.5 \pm 0.007) \mathrm{cm}$ respectively. Further, the average perimeters of left and right optic lobes were measured as $(1.7 \pm 0.339) \mathrm{cm}$ and $(2.0 \pm 0.226) \mathrm{cm}$ respectively. This suggested that the right optic lobe was larger than the left one.

The average length of middle vermis lobe of cerebellum was found to be $(0.9 \pm 0.017) \mathrm{cm}$. The average widths of middle vermis lobe of cerebellum at cranial, middle and caudal parts were measured as $(0.6 \pm 0.003) \mathrm{cm},(0.8 \pm 0.002)$ $\mathrm{cm}$ and $(0.5 \pm 0.001) \mathrm{cm}$ respectively. Similarly, the average thickness of middle vermis lobe of cerebellum at cranial, middle and caudal parts was found to be $(0.5 \pm 0.003)$ $\mathrm{cm}, \quad(0.3 \pm 0.002) \mathrm{cm}$ and $(0.2 \pm 0.001) \mathrm{cm}$ respectively. Further, the average perimeter of this lobe of cerebellum was measured as $(2.6 \pm 0.194) \mathrm{cm}$. The average maximum width of transverse groove located between the cerebrum and cerebellum was found to be $(2.6 \pm 0.125) \mathrm{cm}$.

Study on avian brain will usher a path to the neuro-anatomists to investigate general principles of the nervous system in respect to development behavior, physiology, anatomy and molecular biology. The avian models can be used to decipher many unknown facts about neuronal mechanism underlying various cognitive functions such as memory, learning, consciousness and attention. The gross morphometry of brain of Kadaknath fowl at grower period was successfully studied here. The baseline data developed could be useful for further research.

\section{Acknowledgement}

The Authors are very much grateful to the Director, CPDO, Bhubaneswar for providing the birds to rear and carry out the research 
work in KVK, Jharsuguda, OUAT. The Authors appreciate the co-operation of the faculties and students of Department of Anatomy and Histology, CVSc. \& A.H., OUAT, Bhubaneswar for their necessary inputs.

\section{References}

Bendapudi, R.K. 2016. Strengthening Backyard Poultry Rearing: Approach and results from a pilot project in Jhabua, Madhya Pradesh. South Asia Pro Poor Livestock Policy Programme; A joint initiative of National Dairy Development Board (India) and Food and Agriculture Organisation of the United Nations.

Das, S., Dhote, B.S., Singh, G.K. and Sinha, S. 2017. Histomorphological and micrometrical studies on the proventriculus of Kadaknath fowl. Journal of Entomology and Zoology Studies. 5(3):1560-1564.

Kumar. A., Tigga, R., Bharti, A. and Kumar, R. 2018. Role of Krishi Vigyan Kendras in Conservation and Promotion of Kadaknath Poultry Breed through Backyard Rearing for Livelihood Security of Tribal Farmers in Chhattisgarh. International Journal of Current Microbiology and Applied
Sciences. Special Issue 7: 1194-1200.

Mahanta, D., Mrigesh, M., Sathapathy, S., Tamilselvan, S., Pandit, K. and Nath, S. 2018. Gross and morphometrical studies on the thymus, spleen and bursa of Fabricius of day old Kadaknath chick. Journal of Entomology and Zoology Studies. 6(3):555-558.

Panigrahy, K.K., Behera, K., Mandal, A.K., Sethy, K., Panda, S., Mishra, S.P., Singh, A.K. and Sahu, S.K. 2017. Gross morphology and encephalization quotient of brain in male and female Vanaraja chickens at different ages. Explor Anim Med Res. 7(1): 28-32.

Parmar, S.N.S. 2003. Characterization of Kadaknath breed of Poultry (Famous Black Bird of Jhabua). Technical Bullettin, DRS, JNKVV, Jabalpur (MP).

Tamilselvan, S., Dhote, B.S., Singh, I., Mrigesh, M., Sathapathy, S., Mahanta, D. 2018. Gross morphology of testes and gonadosomatic index (GSI) of guinea fowl (Numida meleagris). Journal of Entomology and Zoology Studies. 6(3):156-159.

Snedecor, G.W. and Cochran, W.G. 1994. In Statistical methods $8^{\text {th }}$ Edn. Oxford and IBH Publishing House, Calcutta.

\section{How to cite this article:}

Joshi, S. K., J. Udgata, S. Sathapathy and Sahu, S. K. 2019. Gross Morphometrical Studies on the Brain of Kadaknath Fowl in Growing Period. Int.J.Curr.Microbiol.App.Sci. 8(09): 12011204. doi: https://doi.org/10.20546/ijcmas.2019.809.137 